\title{
HUBUNGAN TINGKAT PENGETAHUAN DENGAN PEMBERIAN ASI EKSKLUSIF DI DESA GEBANG KABUPATEN BANGKALAN
}

\author{
The Correlation Of Knowledge Level With Exclusive Breastfeeding In Gebang Village, Bangkalan \\ Regency
}

\author{
Wiwik Widiyawati ${ }^{1}$, Lailatul Qamariah1 ${ }^{2}$ \\ ${ }^{1,2}$ Program Studi Ilmu Keperawatan Universitas Muhammadiyah Gresik \\ Alamat Korespondensi : Prodi Ilmu Keperawatan dan Ners UMG \\ Jl. Proklamasi No. 54 Gresik, JawaTimur - Indonesia \\ E-mail: wiwikwidiyawati@umg.ac.id
}

\begin{abstract}
ABSTRAK
Masih banyak ibu yang tidak tahu manfaat ASI eksklusif sehingga pemberian ASI eksklusif masih rendah. Tujuan penelitian ini untuk menganalisis hubungan tingkat pengetahuan dengan pemberian ASI Eksklusif.

Penelitian yang digunakan adalah analitik korelasional, dengan jenis penelitian cross sectional dan pendekatan retrospektif. Populasinya adalah semua ibu yang memiliki bayi usia 7-12 bulan. Teknik pengambilan sampel menggunakan simple random sampling dan pengumpulan data menggunakan kuesioner. Hasil penelitian kemudian dianalisis menggunakan uji koefisien kontingensi lambda.

Hasil penelitian Univariat menunjukkan pengetahuan ibu kurang sebanyak 14 ibu (40\%), ibu tidak memberikan ASI eksklusif sebanyak $25 \mathrm{ibu}$ (71\%). Hasil analisis bivariat hubungan tingkat pengetahuan ibu terhadap pemberian ASI Eksklusif diperoleh p value $(0,023)<\alpha(0,05)$ yang berarti $\mathrm{H} 0$ ditolak $\mathrm{H} 1$ diterima. Diharapkan adanya upaya untuk meningkatkan pengetahuan dan pemahaman tentang pentingnya ASI eksklusif agar pemberian ASI eksklusif dapat meningkat.
\end{abstract}

Kata kunci : pengetahuan, ASI eksklusif

\section{ABSTRACT}

Still many mother did not know the benefits of exclusive breastfeeding, so exclusive breastfeeding is still low. The purpose of this study is to analyze the correlation between the level of knowledge with exclusive breastfeeding.

The study used correlational analytic, with a cross-sectional type of research and a retrospective approach. The population is all mothers who have babies aged 7-12 months. The technique used in this research is simple random sampling and the data collection used a questionnaire. The results of the study analyzed by using the lambda contingency coefficient test.

Univariate research showed that there were 14 mother with less knowledge (40\%), mothers did not give exclusive breastfeeding 25 mother (71\%). The results of the bivariate analysis of the relationship between the level of mother's knowledge towards exclusive breastfeeding were obtained $p$ value $(0.023)<\alpha(0.05)$ which means that $H 0$ rejected $H 1$ was accepte. Hopefully, there is efforts and creation to increase knowledge and understanding of the importance of exclusive breastfeeding to increase exclusive breastfeeding.

Keywords : knowledge, breasfeeding exclusive 


\section{PENDAHULUAN}

ASI ekslusif adalah pemberian ASI saja tanpa makanan-minuman lain sampai bayi berusia 6 bulan, kemudian pemberian ASI harus tetap dilanjutkan sampai bayi berusia 2 tahun walaupun bayi sudah makan (DinKes Jatim, 2016). Pemberian ASI Eksklusif pada bayi merupakan cara terbaik bagi peningkatan kualitas Sumber Daya Manusia (SDM) sejak dini. Banyak faktor yang berhubungan dengan praktek menyusui eksklusif, diataranya adalah kurangnya pengetahuan dan kesadaran ibu akan pentingnya pemberian ASI secara eksklusif, pelayanan kesehatan dan petugas kesehatan yang belum sepenuhnya mendukung program Peningkatan Penggunaan Air Susu Ibu (PP-ASI), gencarnya promosi susu formula, rasa percaya diri ibu yang masih kurang, tingkat pendidikan ibu, dukungan suami dan rendahnya pengetahuan ibu tentang manfaat ASI bagi bayi dan ibu (Sartono, 2012).

Menurut WHO tahun 2017 diperoleh data pemberiaan ASI eksklusif pada bayi usia 0-6 sebanyak 40\%. Berdasarkan Dinas Kesehatan Indonesia tahun 2017 diperoleh data pemberian ASI pada bayi usia 0-6 bulan di Indonesia sebesar 34,9\%. \%. Meskipun data yang diperoleh dari Dinas Kesehatan (DinKes) Jawa Timur tahun 2017 menunjukkan bahwa persentase pemberian ASI mengalami peningkatan dari tahun 2016 (75,7\%). Namun, secara keseluruhan belum memenuhi target yang telah ditetapkan yaitu, 77\%. Melalui data dari Dinas Kesehatan Jawa Timur, 2017 diketahui bahwa prevalensi pemberian ASI eksklusif terendah di Kabupaten Bangkalan yakni, 55,2\%. Cakupan tersebut masih sangat rendah bila dibandingkan dengan target Indonesia sehat sebesar 80\% (DinKes Jatim, 2017).

Rendahnya pemberian ASI eksklusif dan tingginya pemberian MP-ASI dini dikarenakan oleh tiga faktor yaitu faktor presisposisi, faktor pendukung, dan faktor pendorong. Program peningkatan pemberian ASI menjadi prioritas karena dampaknya yang luas terhadap status gizi dan kesehatan bayi, upaya peningkatan kualitas hidup manusia harus dimulai sejak dini yaitu sejak masih dalam kandungan hingga usia balita. Pada masa kehamilan perlu dipersiapkan tentang pengetahuan, sikap, perilaku dan keyakinan ibu tentang menyusui, asupan gizi yang cukup, perawatan payudara dan persiapan mental agar mereka siap secara fisik dan psikis untuk menerima, merawat dan menyusui bayinya sesuai dengan anjuran pemberian ASI eksklusif hingga bayi berusia enam bulan dan tetap menyusui hingga anaknya berusia 24 bulan. IMD dalam 30 menit pertama kelahiran merupakan salah satu dari 10 langkah menuju keberhasilan menyusui (Widiyanto, 2012).

Berdasarkan ulasan diatas maka, tujuan penelitian ini adalah untuk menganalisis hubungan tingkat pengetahuan dengan pemberian ASI eksklusif.

\section{METODE}

Jenis penelitian yang dilakukan merupakan penelitian yang bersifat analitik dengan rancangan penelitian cross sectional. Rancangan penelitian ini menekankan waktu 
pengukuran/ observasi data variabel independen dan dependennya satu kali pada satu saat. Pendekatan yang digunakan pada rancangan penelitian ini adalah pendekatan retrospektif (Nursalam, 2017). Teknik sampling menggunakan sampel random sampling sehingga yang menjadi sampel penelitian berjumlah 35 responden dengan kriteria inklusi yaitu bersedia menjadi responden, memiliki bayi berusia 7-12 bulan. Metode pengumpulan data menggunakan observasi, wawancara.

\section{HASIL DAN PEMBAHASAN}

1. Data Umum

Tabel 1.Distribusi frekuensi responden

\begin{tabular}{lcc}
\hline Karakteristik & $\mathrm{f}$ & $\%$ \\
\hline Umur ibu & & \\
- < 20 tahun & 2 & 6 \\
- 20-30 tahun & 24 & 69 \\
- > 30 tahun & 9 & 26 \\
\hline Umur bayi & & \\
- 7-8 bulan & 18 & 51 \\
- 9-10 bulan & 8 & 23 \\
- 11-12 bulan & 9 & 26 \\
\hline Pendidikan & & \\
- SD & 17 & 49 \\
SMP & 12 & 34 \\
- SMA & 6 & 17 \\
\hline Pekerjaan & & \\
\hline IRT & & $\mathbf{1 0 0}$ \\
\hline - Swasta & 29 & \\
\hline
\end{tabular}

Sumber data : Data primer (2020)
Dari data diatas didapat bahwa responden sebagian besar berumur 20-30 tahun (69\%), dengan pendidikan terakhir yang ditempuh SD 51\%, dan pekerjaan sebagai ibu rumah tangga $83 \%$.

\section{Data Khusus}

\section{Tingkat Pengetahuan Ibu tentang ASI Eksklusif}

Tabel 2. Pengetahuan Ibu tentang ASI Eksklusif

\begin{tabular}{ccc}
\hline Pengetahuan & (f) & (\%) \\
\hline Baik & 8 & 23 \\
Cukup & 13 & 37 \\
Kurang & 14 & 40 \\
\hline Total & 35 & 100 \\
\hline
\end{tabular}

Hasil penelitian menunjukkan bahwa terdapat $14 \mathrm{ibu}$ dengan tingkat pengetahuan kurang tentang ASI eksklusif (40\%) dan $13 \mathrm{ibu}$ dengan pengetahuan cukup tentang ASI eksklusif (37\%) dan 8 ibu dengan pengetahuan baik ASI eksklusif (23\%).

Menurut Notoatmodjo, 2007 dalam Handayani, 2014 Pengetahuan merupakan faktor penting dalam penentuan cara atau metode pemberian ASI pada bayi. Kurangnya pengetahuan ibu mengenai pentingnya ASI yang menjadikan penyebab atau masalah dalam peningkatan pemberian ASI eksklusif. Menurut Purwanti, 2004 dalam Handayani, 2014 mengemukakan bahwa ibu yang memiliki pengetahuan kurang tentang pentingnya pemberian ASI eksklusif cenderung tidak memberikan ASI eksklusif dan beranggapan makanan pengganti ASI dapat membantu ibu dan bayinya, sehingga ibu 
tidak memberikan ASI secara ekslusif kepada bayinya.

Pengetahuan merupakan dasar seorang individu untuk mengambil keputusan dan menentukan tindakan terhadap masalah yang dihadapi, termasuk masalah kesehatan. Pengetahuan tentang kesehatan dapat diperoleh melalui pendidikan formal, penyuluhan maupun informasi media massa. Dengan adanya pengetahuan tentang ASI eksklusif maka akan timbul kesadaran dan mempengaruhi sikap terhadap pemberian makanan prelakteal. Pengetahuan juga berfungsi sebagai motivasi dalam bersikap dan bertindak termasuk dalam penolakan pemberian makanan prelakteal (Rahman, 2017).

Tingkat pengetahuan bukanlah satusatunya faktor dalam pemberian ASI eksklusif, namun pengetahuan perlu dikembangkan untuk mengarahkan ibu dalam pemberian ASI eksklusif. Pengetahuan yang baik tentang ASI akan menimbulkan kesadaran yang akan mempengaruhi ibu dalam pemberian ASI eksklusif. Kurangnya pengalaman ibu juga dapat menyebabkan rendah dalam pemberian ASI eksklusif. Pengalaman juga tidak harus didapat secara formal tetapi juga bisa didapat pada saat ibu sedang hamil ibu akan mendapatkan pengarahan dari petugas kesehatan. Maka pengetahuan ibu tentang ASI eksklusif akan bertambah. Rendah tingkat pengetahuan ibu disebabkan oleh beberapa faktor seperti, pendidikan.

Hal ini sesuai dengan tabel 5.3 persentase pendidikan ibu hampir setengahnya (49\%) ibu berpendidikan SD. Pendidikan merupakan salah satu faktor yang mempengaruhi seseorang berperilaku, termasuk berperilaku dalam pemberian ASI eksklusif (Notoadmojo, 2007 dalam Rumiasari, 2012). Pendidikan yang dijalani ibu memiliki pengaruh pada peningkatan kemampuan berfikir, dengan kata lain ibu yang berpendidikan lebih tinggi akan dapat mengambil keputusan yang lebih rasional, akan dapat menerima perubahan ataupun hal baru dibandingkan dengan ibu yang berpendidikan lebih rendah. Pendidikan perlu untuk mendapatkan informasi seperti hal-hal yang menunjang kesehatan khususnya pemberian ASI eksklusif sehingga dapat meningkatkan kualitas hidup.

\section{Pemberian ASI Eksklusif}

Tabel 3. Pemberian ASI

\begin{tabular}{|c|c|c|}
\hline Pemberian ASI & (f) & $(\%)$ \\
\hline ASI Eksklusif & 10 & 29 \\
\hline Tidak & & \\
\hline Eksklusif & 25 & 71 \\
\hline Total & 35 & 100 \\
\hline
\end{tabular}

Berdasarkan hasil penelitian menunjukkan bahwa terdapat $25 \mathrm{ibu}$ yang tidak memberikan ASI Eksklusif (71\%) dan 10 ibu yang memberikan ASI Eksklusif (29\%). Menurut Markum, 2002 dalam Inggarwati, 2018 menyatakan bahwa pemberian ASI tidak eksklusif ini terjadi karena banyak ibu yang telah memberikan makanan tambahan kepada balita sebelum waktunya. Hal ini bertolak belakang dengan teori yang dikemukakan oleh Roesli, 2015 ASI ekslusif atau lebih tepat pemberian ASI secara eksklusif adalah bayi 
hanya diberi ASI saja, tanpa tambahan cairan lain dan tanpa tambahan makanan padat. Penyebab menurunnya angka pemberian ASI antara lain minimnya pengetahuan para ibu tentang manfaat ASI dan cara menyusui yang benar, (Nuryati, 2007 dalam Rahman, 2017).

ASI sebagai makanan yang terbaik bagi bayi tidak perlu diragukan lagi, namun akhirakhir ini sangat disayangkan banyak diantara ibu-ibu meyusui melupakan keuntungan menyusui. Kondisi ini mencerminkan bahwa perilaku ibu terhadap pemberian ASI eksklusif cenderung kurang baik, apalagi jika melihat indikator Indonesia sehat 2010 dengan cakupan pemberian ASI eksklusif yang ditetapkan adalah $80 \%$. Rendahnya pemberian ASI eksklsuif dipengaruhi oleh pendidikan ibu, umur, status pekerjaan serta keyakinan yang dimiliki.

Rendahnya pendidikan ibu maka ibu akan kurang mendapatkan informasi dan kesulitan dalam mengolah informasi baik yang didapat dari tenaga kesehatan maupun media massa. Pendidikan yang tinggi akan membuat pemahaman pentingnya dan manfaat ASI eksklusif akan semakin baik. Selain itu usia juga mempengaruhi ibu dalam memberikan ASI eksklusif. Oleh sebab itu, yang sesuai dengan masa reproduksi sangat baik dan sangat mendukung dalam pemberian ASI eksklusif. Proses degenerasi payudara mengenai ukuran dan kelenjar alveoli mengalami regresi yang dimulai pada usia 30 tahun, sehingga dengan proses tersebut payudara cenderung kurang menghasilkan ASI (Tory 2011 dalam Estuti, 2012). Status pekerjaan ibu pun dapat menyababkan gagalnya.

\section{Analisis Tingkat Pengetahuan dalam Pemberian ASI Esklskusif}

Tabel 4. Tabulasi silang pengetahuan dengan pemberian ASI Eksklusif

\begin{tabular}{cccccc}
\hline \multirow{2}{*}{$\begin{array}{c}\text { Tingkat } \\
\text { Pengetah }\end{array}$} & \multicolumn{4}{c}{ Asi Eksklusif } & \multicolumn{2}{c}{ Tidak ASI } & Total \\
uan & f & \% & f & \% & \% \\
\hline Kurang & 0 & 0 & 14 & 100 & 100 \\
Cukup & 3 & 23,1 & 10 & 76,9 & 100 \\
Baik & 7 & 87,5 & 1 & 12,5 & 100 \\
Total & $\mathbf{1 0}$ & $\mathbf{2 8 , 6}$ & $\mathbf{2 5}$ & $\mathbf{7 1 , 4}$ & $\mathbf{1 0 0}$ \\
\hline
\end{tabular}

Hasil penelitian menunjukkan bahwa ibu yang tidak memberikan ASI eksklusif dengan tingkat pengetahuan kurang sebesar (100\%) lebih besar dari ibu dengan tingkat pengetahuan cukup $(76,9 \%)$ dan lebih besar dari ibu berpengetahuan baik (12,5\%), sedangkan ibu yang memberikan ASI eksklusif dengan tingkat pengetauan baik (87,5\%) lebih besar dari ibu dengan pengethuan cukup $(23,1 \%)$ dan tidak satupun ibu dengan tingkat pengetahuan kurang.

Dari hasil analisis dengan menggunakan uji koefisien kontigensi lambda dengan menggunakan SPSS 16 for windows didapatkan nilai $\mathrm{p}=0,023<0,05$. Dengan demikian dapat disimpulkan bhawa Ho ditolak Ha diterima yang berarti terdapat hubungan tingkat pengetahuan dengan pemberian ASI Eksklusif pada bayi usia 0-6 bulan.

Menurut Aprilia, 2012 Pengetahuan ibu tentang ASI eksklusif dapat mempengaruhi ibu dalam memberikan ASI eksklusif. Semakin baik pengetahuan Ibu tentang ASI eksklusif, maka seorang ibu akan memberikan ASI 
eksklusif pada anaknya. Begitu juga sebaliknya, semakin rendah pengetahuan ibu tentang ASI eksklusif, maka semakin sedikit pula peluang ibu dalam memberikan ASI eksklusif.

Menurut Sulistiyawati, 2017 mengatakan bahwa pengetahuan ibu mengenai ASI eksklusif dapat diperoleh dari tingkat pendidikan. Pendidikan yang baik mempengaruhi ibu dalam memahami informasi dari berbagai sumber. Adanya informasi tetang ASI eksklusif yang diperoleh ibu baik secara pribadi dan didukung oleh informasi yang diperoleh akan membantu dalam mengetahui dan memahami tentang pengetahuan ASI eksklusif yang baik dan benar. Dengan demikian ibu yang memiliki pengetahuan tinggi adalah ibu yang memberikan ASI eksklusif kepada bayinya. Sedangkan ibu yang memiiki pengetahuan cukup dan kurang kebanyakan tidak memberikan ASI eksklusif kepada bayinya. Dengan demikian pengetahuan ibu mempengaruhi dalam berfikir tentang pemberian ASI eksklusif pada bayinya. Dengan tingginya tingkat pengetahuan ibu maka nantinya akan timbul kesadaran yang dapat mempengaruhi ibu dalam memberikan ASI eksklusif.

Pengetahuan ibu yang kurang tentang ASI Eksklusif dapat dipengaruhi oleh rendahnya pendidikan. Sehingga ibu kurang mendapatkan informasi dan mengalami kesulitan dalam mengolah informasi baik yang didapat dari tenaga kesehatan maupun media massa, dan informasi tentang manfaat asi juga dapat di dapatkan ketika ada posyandu bulanan dari tenaga kesehatan dan ibu-ibu lainnya yang sudah mengerti manfaat asi. begitupun juga bisa di dapatkan dari penyuluhan tentang manfaat asi ekslusif yang selalu di adakan oleh pihak tenaga kesehatan yang bisa kita temukan dirumah sakit. Semakin kita banyak mendapatkan informasi tentang manfaat asi ekslusif semakin kita mengerti kalau asi ekslusif itu banyak manfaatnya. Dan semakin tinggi pendidikan ibu maka semakin besar pula pemahaman ibu terhadap pemberian ASI eksklusif. Pendidikan yang lebih tinggi akan membuat pemahaman pentingnya dan manfaat ASI eksklusif akan semakin baik. Dengan adanya pengetahuan tentang ASI eksklusif maka nantinya akan timbul kesadaran yang dapat mempengaruhi pemberian ASI eksklusif.

\section{PENUTUP}

Ada hubungan tingkat pengetahuan dengan pemberian ASI eksklusif di Desa Gebang Kabupaten Bangkalan, diharapkan masyarakat terutama ibu menjadi lebih aktif dalam mencari informasi mengenai pentingnya pemberian ASI Eksklusif.

\section{UCAPAN TERIMA KASIH}

Ucapan terima kasih kami berikan kepada Kepala Desa Gebang Bangkalan, atas kesempatan, dan bimbingan dalam penelitian.

\section{DAFTAR PUSTAKA}

DinKes Provinsi Jawa Timur 2016. Profil Kesehatan Provinsi Jawa Timur Tahun 2016 
DinKes Provinsi Jawa Timur 2017. Profil Kesehatan Jawa Timur 2017. Bangkalan

Hamdayani L, dkk. 2014. Hubungan Pengetahuan Dan Teknik Menyusui Dengan Pemberian Asi Eksklusif Di Wilayah Kerja Puskesmas Pengasih Ii Kabupaten Kulonprog

Induniasih \& Ratna W. 2017. Promosi Kesehatan Pendidikan Kesehatan dalam Keperawatan. Yogyakarta : Pustaka Baru Press

Notoatmodjo S. 2010. Ilmu Perilaku Kesehatan. Jakarta : PT Rineka Cipta Nursalam, 2017. Metodologi Penelitian Ilmu Keperawatan. Jakarta : Salemba Medika Rahman, N. 2017. Pengetahuan, Sikap, Dan Praktik Pemberian ASI Eksklusif Di Wilayah Kerja Puskesmas Jumpandang Baru Kecamatan Tallo Kota Makasar

Sari K D, dkk. 2017. Hubungan Teknik Frekuensi, Durasi Menyusui dan Asupan Energi dengan Berat badan bayi Usia 1-6 Bulan di Puskesmas Tasikmadu Kabupaten Karanganyar

Sartono A dan Utaminingrum H. 2012. Hubungan Pengetahuan Ibu, Pendidikan Ibu dan Dukungan Suami dengan Praktek Pemberian Asi Eksklusif di Kelurahan Muktiharjo Kidul Kecamatan Telogosari Kota Semarang

Sulistiyawati I. 2017. Hubungan Tingkat Pengetahuan Ibu dengan Pemberian ASI Eksklusif di Wilayah Kerja Puskesmas Arjasa Kabupaten Jember

Widiyanto. S, dkk. 2012. Hubungan Pendidikan dan Pengetahuan Ibu tentang
ASI Eksklusif dengan Sikap terhadap Pemberian ASI Eksklusif 